\title{
Hızlı Tren Şantiyesinde Çalışanların Güvenlik İklimi Algıları ve İşten Ayrılma Niyetleri Arasındaki İlişkinin İncelenmesi \\ (Investigation of the Relationship Between Perceptions of the Safety Climate of the Employees at the High Speed Train Site and their Intention to Leave Work)
}

\section{Zeynep Feride OLCAY iD a}

a İstanbul Aydın Üniversitesi, İstanbul, Türkiye. zeynepolcay@aydin.edu.tr

\begin{tabular}{l} 
MAKALE BİLGİsí \\
\hline Anahtar Kelimeler: \\
İş Sağlığı ve Güvenliği \\
Güvenlik İklimi \\
İşten Ayrılma Niyeti, Çalışma \\
Psikolojisi
\end{tabular}

Gönderilme Tarihi 28 Temmuz 2021

Revizyon Tarihi 22 Eylül 2021

Kabul Tarihi 25 Eylül 2021

Makale Kategorisi:

Araştırma Makalesi

\section{ÖZET}

Amaç - Bu çalışmanın kapsamında Bilecik hızlı tren şantiyesinde istihdam edilen kişilerin güvenlik iklimi algısıyla işten ayrılma niyeti (IAN) arasındaki ilişkinin incelenmesi amaçlanmaktadır.

Yöntem - Araştırmanın ana kütlesini Bilecik ili hızlı tren şantiyesinde çalışan 185 kişi oluşturmaktadır. Örneklem ise 16-19 Mart 2021 tarihinde anket sorularını cevaplayan 127 katılımcıdan meydana gelmiştir. Anketin etik kurul izni alınmıştır. Yüz yüze uygulanan anket 3 bölümden oluşturulmuştur; ilk bölümde ankete katılan kişilerin sosyo-demografik özelliklerine ilişkin sorular, 2. bölümde güvenlik iklimi ölçeği ve son bölümde işten ayrılma niyeti ölçeği bulunmaktadır. Araştırma kapsamında SPSS 25.0 istatistik paket programı kullanılarak, güvenlik iklimi ve işten ayrılma niyeti ölçeklerinden elde edilen puanların dağılımını incelemek için Shapiro-Wilk normallik testi uygulanmıştır. Sonuçlara göre ölçeklerden elde edilen puanlar normal dağılıma sahip olmadığından verilerin analizinde parametrik olmayan analiz teknikleri kullanılmıştır.

Bulgular - Araştırma sonuçlarına göre katılımcıların işten ayrılma niyeti puanları ile yönetimin bakış açısı ve kurallar $(r=-0,016 ; p>0,05)$, iş arkadaşları ve güvenlik eğilimleri $(r=0,022 ; p>0,05)$ ve güvenlik iklimi ölçeği toplam $(r=-0,001 ; p>0,05)$ puanları arasında istatistiksel olarak anlamlı olmayan ilişkilerin bulunduğu anlaşılmaktadır. Katılımcıların güvenlik iklimi algıları ile işten ayrılma niyeti arasında anlamlı bir ilişki bulunmamakla beraber, elde edilen sonuçlar katılımcıların güvenlik iklimi algılarının yüksek düzeyde, işten ayrılma niyetinin ise orta düzeyde olduğunu göstermiştir. Anketin ilk bölümünde bulunan katılımcıların sosyo-demografik özellikleri ile güvenlik iklimi algısı ve işten ayrılma niyeti arasında ortaya çıkan anlamlı farklılıklar bulgular kısmında paylaşılmaktadır.

Tartışma - Sonuçlara göre güvenlik iklimi algısı ve işten ayrılma niyeti arasında anlamlı bir ilişki saptanmamasına rağmen, yapılan araştırmalarda örgüt ve yapılan işle ilgili, çalışanlarla ilgili ve dış etkenler işten ayrılma niyetinin öncülleri olarak görülmektedir. Bu öncüllerden biri olduğu düşünülen iş güvenliği iklimi algısının işten ayrılma niyeti ile olan ilişkisinin farklı sektör ve çalışma alanlarında araştırılması faydalı olacaktır.

ARTICLE INFO ABSTRACT

\section{Keywords:}

Occupational Health and Safety

Safety Climate

Intention to Leave, Work

Psychology

Received 28 July 2021

Revised 22 September 2021

Accepted 25 September 2021

Article Classification:

Research Article
Purpose- Within the scope of this study, it is aimed to examine the relationship between the safety climate perceptions of the people employed at the Bilecik high-speed train site and their intention to leave the job.

Design/methodology/approach- The main body of the research consists of 185 people working at the high-speed train site in Bilecik. The sample consisted of 127 participants who answered the survey questions on 16-19 March 2021. Ethics committee approval was obtained for the questionnaire. The faceto-face questionnaire was composed of 3 parts; In the first part, there are questions about the sociodemographic characteristics of the people who participated in the survey, in the second part, the safety climate scale and in the last part, the turnover intention scale. Within the scope of the research, the Shapiro-Wilk normality test was applied to examine the distribution of the scores obtained from the safety climate and intention to leave scales by using the SPSS 25.0 statistical package program. According to the results, since the scores obtained from the scales did not have a normal distribution, nonparametric analysis techniques were used in the analysis of the data.

Findings- According to the results of the research, the participants' turnover intention scores, the management's point of view and rules $(\mathrm{r}=-0.016$; $\mathrm{p}>0.05)$, co-workers and safety tendencies $(\mathrm{r}=0.022$; $\mathrm{p}>0.05$ ) and safety climate scale total It is understood that there are statistically insignificant relationships between the scores $(\mathrm{r}=-0.001 ; \mathrm{p}>0.05)$. Although there was no significant relationship between the participants' perceptions of safety climate and their intention to leave, the results showed that

\section{Önerilen Atıf/ Suggested Citation}

Olcay, Z.F. (2021). Hızlı Tren Şantiyesinde Çalışanların Güvenlik İklimi Algıları ve İşten Ayrılma Niyetleri Arasındaki İlişkinin

İncelenmesi, İşletme Araştırmaları Dergisi, 13 (3), 2902-2915. 
participants' perceptions of safety climate were high and their intention to leave their job was moderate. Significant differences between the socio-demographic characteristics of the participants in the first part of the questionnaire, their perception of the safety climate and their intention to leave the job are shared in the findings section.

Discussion- According to the results, although no significant relationship was found between the perception of safety climate and intention to leave, organizational, work-related, employee-related and external factors are seen as antecedents of turnover intention. It would be beneficial to investigate the relationship between the perception of occupational safety climate, which is thought to be one of these antecedents, and the intention to leave the job, in different sectors and work areas.

\section{GİRIŞ}

Sağlıklı ve güvenli çalışma koşulları, iyi ücretlendirme, kariyer gelişim fırsatları ve uygun çalışma saatleri, iş yaşam kalitesi içerisinde yer almaktadır. Yüksek iş yaşam kalitesi işten ayrılma niyetini düşürmektedir (Galetta, 2011). Birçok araştırmacı, bazı yönetsel çıkarımlar sağlamak amacıyla işten ayrılma niyetinin ana belirleyicilerini anlamaya çalışmıştır (Tüzün, 2007). İşten ayrılma niyetini etkileyen faktörler için özellikle iş stresi, iş tatminsizliği, işyerindeki adaletli olmayan durumlar ve iş yaşam kalitesinin düşük olması gösterilebilir (Kaur ve diğerleri (vd.), 2013).

Çalışma ortamında devamlı olarak personel değişimi, yeni personelin işe alınma sürecindeki oryantasyonu ve eğitimleri (Abbasi vd., 2008) maddi ve manevi bazı yükler getireceğinden, işverenler tarafından istenmeyen bir durumdur. Çalışanların işyerine bağlılığını artırmak için onları bulundukları örgütlere ait hissetmelerinin sağlanması büyük önem arz etmektedir. Çalışanların işyeri memnuniyetlerinin sağlanması, İşten ayrılma niyetini etkileyeceği düşünüldüğünde; çalışanların memnuniyetlerini sağlamanın bir etkeni de kendilerinin önemsendiğini hissetmeleridir. İş sağlığı ve güvenliği önlemlerinin alındığı yani güvenlik iklimi algısının yüksek olduğu işletmelerde çalı̧̧anların işten ayrılma niyeti ile arasındaki ilişkinin incelenmesi istenmiştir. Bunun için hızlı tren şantiyesi çalışanlarının çalışma koşullarının zorluğu ve iş güvenliği tehlikelerinin fazla olmasından dolayı, hem iş güvenliği algı düzeyleri, hem de işten ayrılma niyeti ile bunlar arasında bir ilişkinin olup olmadığı araştırılmıştır.

\section{KAVRAMSAL ÇERÇEVE}

\subsection{Güvenlik İklimi}

İlk kez Zohar (1980) tarafından kullanılan güvenlik iklimi kavramı, belirli bir zamanda, işyerinde güvenlik yönetiminin nasıl operasyonel hale getirildiğine dair paylaşılan çalışan algıları olarak tanımlanmaktadır (Byrom ve Corbridge, 1997). Güvenlik kültürünün bir göstergesi olarak kullanılan güvenlik iklimi, güvenlik yönetimi kaynaklarının, yani kurallar, uygulamalar ve süreçlerin etkinliğini etkilemektedir (Cox ve Cheyne, 2000). Güvenlik kültürünün bir yansıması olan güvenlik iklimi (Guldenmund, 2000; Cox ve Flin, 1998; Lee ve Harrison, 2000) çalışma ortamında güvenliğin değerine ilişkin bireysel algıları tanımlayan özel bir organizasyonel iklim biçimidir (Neal vd., 2000).

Cooper' a göre (2000) güvenlik kültürünün bir alt bileşeni olan güvenlik ikliminin değerlendirilmesi işletmeler için avantaj sağlamaktadır. Çünkü işletmelerin güvenlik koşullarını proaktif olarak izlemelerini ve sistem arızalanmadan önce düzeltici önlemler almalarını sağlar (Flin, 1988). İşletmeler genellikle olumlu bir güvenlik ortamı oluşturarak işyeri kazalarını ve yaralanmalarını önlemeye çalışırlar (Zohar, 1980). Olumlu bir güvenlik ortamının, güvenlik uyumu ve katılımını artırmakla beraber, işyeri kazaları ve yaralanmalarının azalmasında etkili olduğu bilinmektedir (Clarke, 2010). Olumlu bir güvenlik iklimi altında, çalışanların güvenli olmayan eylemlerde bulunma olasılıkları daha düşüktür (Hofmann ve Stetzer, 1996).

Çalışma ortamında pozitif bir iş güvenliği iklimi oluşturabilmek için, hem yöneticiler hem de çalışanlara bazı sorumluluklar düşmektedir. Çalışanlara rol model olabilmeleri açısından yöneticilerin iş güvenliği konusunda yapılan tüm faaliyetlere katılmaları ve devamlı olarak iş güvenliğine verilen önemi vurgulamaları gerekmektedir (Zohar, 1980). İşyerinde iş güvenliği yönetim sistemi kurularak, güvenlik politikası ve prosedürlerin oluşturulması, iş güvenliğinin kontrolü ve izlenmesinin sağlanması verimli bir iletişim akışı sağlayacağı gibi çalışanların güvenlik iklimi algısını da artıracaktır (Health and Safety Exucitive, 2005). 


\section{2. İşten Ayrılma Niyeti}

İşten ayrılma niyeti, çalışanın devamlı ve bilinçli bir biçimde bulunduğu kurumdan ayrılma isteği ve bu isteğe bağlı olarak ortaya çıkan ayrılma kararı olarak tanımlanmaktadır (Tett ve Meyer, 1993). Bir başka açıklamaya göre ise, kişinin çalıştığı kurumdan ayrılma ya da kurumda çalışmaya devam etme kararının değerlendirilmesi şeklinde ifade edilmektedir (Güzel, 2019). İşten ayrılma niyeti, kişilerin iş yerinden duyduğu memnuniyetsizlik, iş yaşamındaki çatışmalar ve işletme içinde önemsenmeleri ile ilgilidir (Matilla, 2006). Başka bir tanıma göre çalışanların yakın bir gelecekte çalıştığı kurumda daha fazla bulunmak istememe düşüncesi (Mobley,1982) olan İşten ayrılma niyeti yıkıcı bir eylemdir ve çalışanlar işlerinden memnun olmadıklarında bu aktif eylemi gerçekleştirebilirler (Rusbult vd., 1988).

Cho vd. göre (2009) çalışanın bilinçli olarak çalıştığı iş yerinden ayrılmaya istekli olması olarak ifade edilen İşten ayrılma niyeti, bir çalışanın mevcut işten ayrılma ve yakın bir zamanda farklı bir iş bulma niyetine yönelik planı" olarak tanımlanmaktadır (Weisberg, 1994).

İşten ayrılma durumu, kişinin çalıştığı kurumdan fiili anlamda ilişiğini kesmesi olarak kabul edilirken, İşten ayrılma niyeti ise çalışanın davranışsal tutum olarak kurumdan ayrılma isteğidir (Telli vd., 2012). İşten ayrılma niyeti olan çalışan, işten ayrılabileceği gibi bu niyet tam tersi yönde de sonuçlanabilmektedir (Jafarova, 2018). İşten ayrılma niyeti gönüllü ayrılma ve gönülsüz ayrılma şeklinde ikiye ayrılmaktadır. Gönüllü ayrılma, bireysel faktörlerle birlikte, alternatif iş fırsatları, iş tatminsizliği, ücret gibi unsurlardan dolayı örgüt üyesinin kendi isteği doğrultusunda işten ayrılmak istemesidir. Gönülsüz ayrılma ise, bir sebepten dolayı işveren tarafından kişinin işine son verilmesidir (Chang ve Chang, 2008)

Literatür çalışmalarında örgütsel bağlılık ile işten ayrılma niyeti arasındaki ilişkiyi kanıtlayan çok sayıda araştırma bulunmaktadır (Tanveer, 2013). Çalışanlar kariyer planlarındaki engeller, uygunsuz çalışma şartları, uzun çalışma saatleri, yöneticilerle olan iletişim eksikliği, iş stresi ya da daha iyi koşullarda çalışabilecekleri işletmelere geçmek istedikleri gibi farklı nedenlerden kaynaklı olarak işten ayrılma niyetine girebilmektedirler (Bartlett 1999; Fallon ve Rutherford, 2010).

\section{YÖNTEM}

\subsection{Araştırmanın Modeli}

Araştırmanın modeli şekil 1'de yer almaktadır.

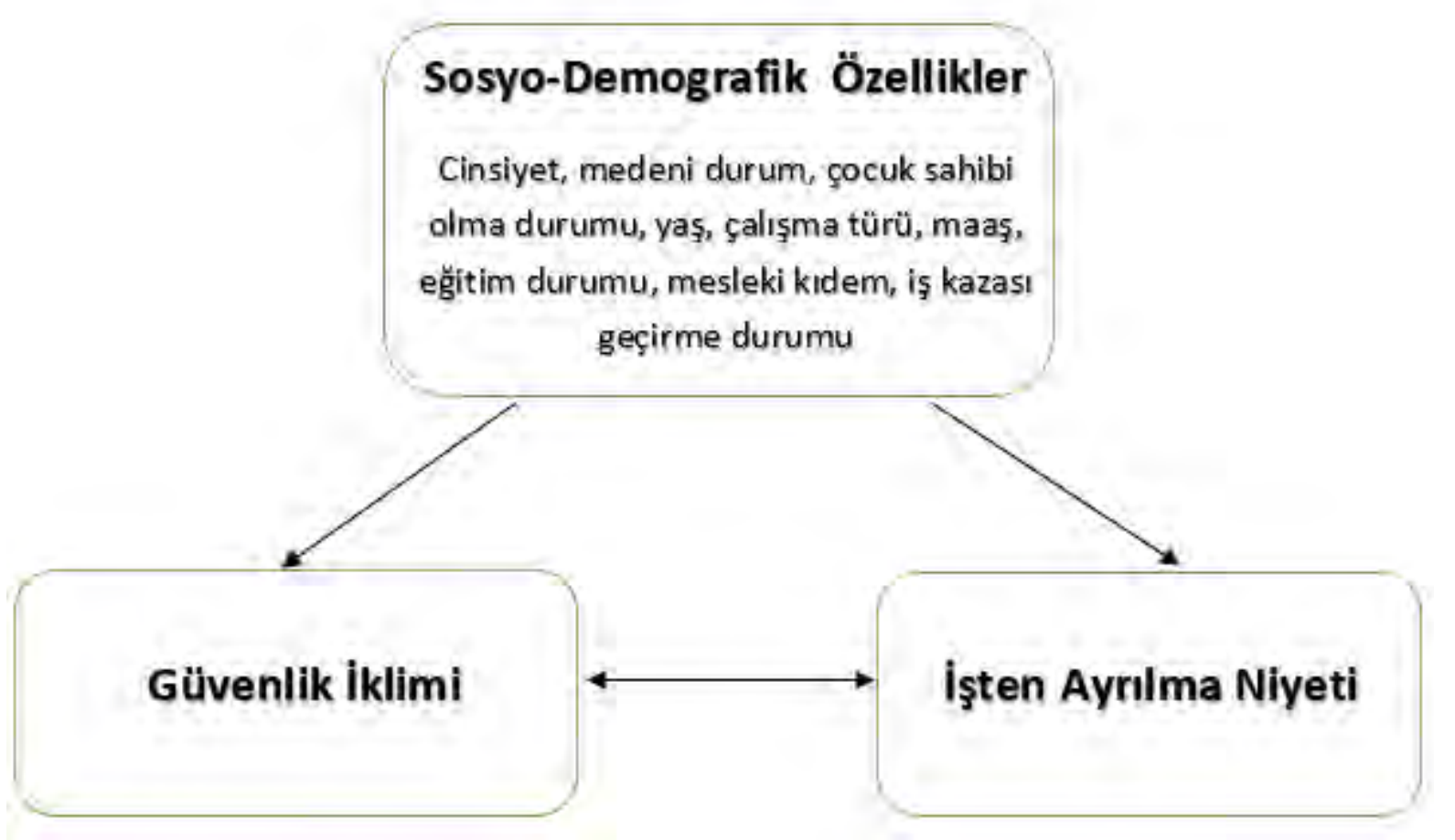

Şekil 1: Araştırmanın Modeli 


\subsection{Evren ve Örneklem}

Araştırmanın evreni 16-19 Mart 2021 tarihleri arasında Bilecik Hızlı Tren Projesi'nde çalışan 185 kişiden meydana gelmektedir. Pandemi sürecinden dolayı çalışan sayısında azaltma durumuna gidilmesi araştırmanın sınırlılığını oluşturmaktadır. Örneklem seçiminde, oluşturulan evren listesinden örnekleme birimlerinin seçkisiz olarak seçilmesi (Büyüköztürk vd., 2017) ilkesine dayanan basit seçkisiz örnekleme yöntemi kullanılmıştır. Araştırmanın örneklemini ise bu yöntemle seçilen 127 çalışan oluşturmaktadır. Basit seçkisiz örnekleme formülünde \% 95 güven aralığı ve 0,05 hata payına göre evren büyüklüğünün 185 olduğu durumda, örneklem sayısının en az 125 olması gerekmektedir. Örneklem hesabında kullanılan formül aşağıda bulunmaktadır (Karasar, 2014);

$n=\frac{N * t^{2} * p * q}{d^{2} *(N-1)+t^{2} * p * q} \quad$ Denklem (1)

N: Evren büyüklüğü,

n: Örneklem büyüklüğü,

$\mathrm{t}$ : Belirli bir anlamlılık düzeyinde $\mathrm{t}$ tablosuna göre bulunan teorik değer,

p: İncelenen olayın gerçekleşme olasılı̆̆g,

q: İncelenen olayın gerçekleşmeme olasılı̆̆ı,

d: Hata pay1

Araştırmada \%95 güven aralığı ve 0,05 hata payı ile t değeri 1,96'ya eşittir. Araştırma verileri denklem 1 'de yerine konulduğunda örneklem büyüklüğünün en az 125 olması gerekmektedir.

Hesaplanan örneklem büyüklüğünün istatistiki ölçümler sonucu \%95 olasılık ile \%5'lik bir hata payı dikkate alınarak evreni temsil etmek için yeterli olduğu görülmektedir (Gürbüz ve Şahin, 2016).

\subsection{Veri Toplama Araçları}

Anket üç bölümden oluşmaktadır. Birinci bölümde kişilerin sosyo-demografik özelliklerine ait 11 sorudan oluşan kişisel bilgi formu bulunmaktadır. İkinci bölümde güvenlik iklimi ölçeği ve üçüncü bölümde ise İşten ayrılma niyeti ölçeğine yer verilmiştir.

\subsubsection{Kişisel Bilgi Formu}

Birinci bölümde cinsiyet, medeni durum, yaş, eğitim durumu, çalışma türü, mesleki tecrübe ve iş kazası geçirme durumu gibi sorulara yer verilmiştir.

\subsubsection{Güvenlik İklimi Ölçeği}

İkinci bölümde katılımcıların çalıştıkları işyerinde algıladıkları iş güvenliği düzeyini ölçmek için, Choudhry, Fang ve Mohamed (2007) tarafından geliştirilmiş, sonra Türen vd.'nin (2014) geçerlilik güvenirliğini yaptıkları iki alt boyut ve 14 sorudan oluşturulmuş "Güvenlik İklimi Ölçeği” kullanılmıştır.

\subsection{3. İşten Ayrılma Niyeti Ölçeği}

Üçüncü bölümde ise, İAN' nin ölçülmesinde ise Blau ve Boal'ın (1989) geliştirdiği, Deliorman vd. (2009) tarafından geçerlilik ve güvenirliğinin yapıldı̆̆ı tek boyut ve 3 sorudan meydana gelen "İşten Ayrılma Niyeti Ölçeği!"' bulunmaktadır.

\subsection{Verilerin Analizi}

Araştırma kapsamında, güvenlik iklimi ölçeği (GïÖ) ve işten ayrılma niyeti (İAN) ölçeğinden elde edilen puanların dağılımını incelemek için Shapiro-Wilk normallik testi uygulanmıştır. Test sonuçlarına göre ölçeklerden elde edilmiş puanlar normal dağılımlı değildir (Tablo 1). Bu doğrultuda verileri analiz etmek için parametrik olmayan analiz teknikleri kullanılmıştır.

Tablo 1. Normallik Testi Sonuçları

\begin{tabular}{llll}
\hline \multirow{2}{*}{ Değişkenler } & Shapiro-Wilk & & \\
\cline { 2 - 4 } & $\mathrm{z}$ & $\mathrm{Sd}$ & $\mathrm{P}$ \\
\hline Yönetimin Bakış Açısı ve Kurallar & 0,79 & 127 & 0,00 \\
İş Arkadaşları ve Güvenlik Eğilimleri & 0,75 & 127 & 0,00 \\
GïÖ toplam puan & 0,77 & 127 & 0,00 \\
İAN & 0,92 & 127 & 0,00 \\
\hline
\end{tabular}


Güvenlik iklimi ve İAN ölçeklerinden elde edilen puanları medeni durum, cinsiyet, çalışma türü, çocuk sahibi olma durumu, mesleki hayatında iş kazası geçirme durumu, mevcut firmada iş kazası geçirme durumu değişkenlerine göre karşılaştırmak için Mann-Whitney U testi uygulanmıştır. Ölçek puanlarını yaş, net maaş, eğitim durumu, mesleki tecrübe ve mevcut firmada çalışma süresi değişkenlerine göre karşılaştırmak için Kruskal Wallis H testi uygulanmıştır. Farkın kaynağını belirlemek için ikili karşılaştırmalar yapılmış ve Bonferroni düzeltmesi yapılarak sonuçlar raporlanmıştır. Güvenlik iklimi ve İAN ölçeklerinden elde edilen puan arasındaki ilişkileri incelemek için Spearman korelasyon katsayıları hesaplanmıştır. \%95 olarak belirlenmiş güven aralığında ve $p<0,05$ değerleri anlamlı kabul edilmiştir. SPSS 25.0 istatistik paket programından faydalanılarak verilerin analizi yapılmıştır.

\section{BULGULAR}

\subsection{Katılımcılara Ait Bilgiler}

Tablo 2. Katılımcıların Tanılayıcı Özelliklere Göre Dağılımı

\begin{tabular}{|c|c|c|c|}
\hline & & $\mathrm{F}$ & $\%$ \\
\hline \multirow{2}{*}{ Cinsiyet } & Kadın & 17 & 13,4 \\
\hline & Erkek & 110 & 86,6 \\
\hline \multirow{2}{*}{ Medeni durum } & Evli & 68 & 53,5 \\
\hline & Bekar & 59 & 46,5 \\
\hline \multirow{2}{*}{ Çocuğunuz var mı? } & Evet & 59 & 46,5 \\
\hline & Hayır & 68 & 53,5 \\
\hline \multirow{5}{*}{ Yaş grubu } & $18-25$ & 17 & 13,4 \\
\hline & $26-33$ & 31 & 24,4 \\
\hline & $34-41$ & 26 & 20,5 \\
\hline & $42-49$ & 41 & 32,3 \\
\hline & 50 ve üzeri & 12 & 9,4 \\
\hline \multirow{2}{*}{ Çalışma türü } & $\mathrm{AF}$ & 52 & 40,9 \\
\hline & $\mathrm{TF}$ & 75 & 59,1 \\
\hline \multirow{5}{*}{ Net maaş } & 3000 TL ve altı & 8 & 6,3 \\
\hline & 3001-4000 TL & 34 & 26,8 \\
\hline & $4001-5000 \mathrm{TL}$ & 40 & 31,5 \\
\hline & 5001-6000 TL & 21 & 16,5 \\
\hline & 6001 TL ve üstü & 24 & 18,9 \\
\hline \multirow{5}{*}{ Eğitim durumu } & İlkokul & 45 & 35,4 \\
\hline & Ortaokul & 32 & 25,2 \\
\hline & Lise & 16 & 12,6 \\
\hline & Ön lisans & 9 & 7,1 \\
\hline & Lisans & 25 & 19,7 \\
\hline \multirow{4}{*}{ Mesleki tecrübe } & 1 yıldan az & 7 & 5,5 \\
\hline & $1-3$ yil & 9 & 7,1 \\
\hline & $3-5$ yil & 24 & 18,9 \\
\hline & 5 yıl ve üzeri & 87 & 68,5 \\
\hline \multirow{3}{*}{ Mevcut firmadaki çalışma süresi } & 3 yıl ve daha az & 38 & 29,9 \\
\hline & $3-5$ yil & 22 & 17,3 \\
\hline & 5 yil ve üzeri & 67 & 52,8 \\
\hline \multirow{2}{*}{ Meslek hayatı iş kazası geçirme durumu } & Evet & 24 & 18,9 \\
\hline & Hayır & 103 & 81,1 \\
\hline \multirow{3}{*}{ Firmada iş kazası geçirme durumu } & Evet & 48 & 37,8 \\
\hline & Hayır & 79 & 62,2 \\
\hline & Toplam & 127 & 100,0 \\
\hline
\end{tabular}

Tablo 2 incelendiğinde, katılımcıların \%13,4'ünün kadın, \%86,6'sının erkek olduğu anlaşılmaktadır. Evli katılımcıların oranı \%53,5'tir. Katılımcların \%13,4'ünün 18-25, \%24,4'ünün 26-33, \%20,5'inin 34-41, 
\%32,3'ünün 42-49 ve \%9,4'ünün 50 ve üzeri yaş grubunda bulunduğu gözlenmiştir. Ana firmada çalışan katılımcıların oranı $\% 40,9$ taşeron firmada çalışan katılımcıların oranı ise $\% 59,1^{\prime}$ dir.

Katılımcıların \%6,3'ü 3000 TL ve altı, \%26,8' i 3001-4000 TL, \%31,5'i 4001-5000 TL, \%16,5'i 5001-6000 TL, \%18,9'u 6001 TL ve üstü net gelire sahip olduğunu ifade etmiştir. Katılımcıların büyük bir oranı ilkokul $(\% 35,4)$ ve ortaokul $(\% 25,2)$ mezunudur. Katılımcıların büyük bir oranı 5 yıl ve daha fazla tecrübeye $(\% 68,5)$, sahiptir ve mevcut firmalarında 5 yıl ve üzeri $(\% 52,8)$ süre ile çalışmaktadır. Katılımcıların \%81,1'inin meslek hayatında kaza geçirmediği ve \%62,2'sinin mevcut firmalarında kaza geçirmediği anlaşılmaktadır.

Tablo 3. Güvenlik İklimi ve İAN Ölçeklerinden Elde Edilen Puanlarına Ait Betimsel Değerler

\begin{tabular}{llllll}
\hline Değişkenler & $\mathrm{N}$ & Minimum & Maksimum & Ort & Ss \\
\hline Yönetimin Bakış Açısı ve Kurallar & 127 & 13 & 50 & 41,91 & 8,65 \\
İş Arkadaşları ve Güvenlik Eğilimleri & 127 & 4 & 20 & 17,14 & 3,49 \\
GíÖ toplam puan & 127 & 19 & 70 & 59,06 & 11,85 \\
İAN & 127 & 3 & 15 & 8,88 & 4,04 \\
\hline
\end{tabular}

Tablo 3 incelendiğinde Yönetimin Bakış Açısı ve Kurallar, İş Arkadaşları ve Güvenlik Eğilimleri, GïÖ toplam puan ve İAN puan ortalamaları sirasiyla $41,91(\mathrm{Ss}=8,65), 17,14(\mathrm{Ss}=3,49), 59,06(\mathrm{Ss}=11,85)$ ve 8,88 $(\mathrm{Ss}=4,04)$ olarak hesaplanmıştır. Elde edilen sonuçlar katılımcıların iş güvenliği algılarının yüksek düzeyde, İAN' nin ise orta düzeyde olduğunu göstermiştir.

Tablo 4. Cinsiyete Göre Güvenlik İklimi ve İAN Puanlarının Mann-Whitney U Testi ile Karşılaştırılması

\begin{tabular}{llllllll}
\hline Değişkenler & Cinsiyet & $\mathrm{N}$ & $\mathrm{SO}$ & $\mathrm{ST}$ & $\mathrm{U}$ & $\mathrm{Z}$ & $\mathrm{p}$ \\
\hline \multirow{2}{*}{ Yönetimin Bakış Açısı ve Kurallar } & Kadın & 17 & 77,41 & 1316,00 & \multirow{2}{*}{707,00} & \multirow{2}{*}{$-1,62$} & \multirow{2}{*}{0,10} \\
& Erkek & 110 & 61,93 & 6812,00 & & & \\
\hline \multirow{2}{*}{ İş Arkadaşları ve Güvenlik Eğilimleri } & Kadın & 17 & 82,91 & 1409,50 & \multirow{2}{*}{613,50} & \multirow{2}{*}{$-2,34$} & \multirow{2}{*}{0,02} \\
& Erkek & 110 & 61,08 & 6718,50 & & & \\
\hline \multirow{2}{*}{ GïÖ toplam puan } & Kadın & 17 & 79,32 & 1348,50 & \multirow{2}{*}{674,50} & \multirow{2}{*}{$-1,85$} & \multirow{2}{*}{0,06} \\
& Erkek & 110 & 61,63 & 6779,50 & & \\
\hline \multirow{2}{*}{ İAN } & Kadın & 17 & 65,12 & 1107,00 & \multirow{2}{*}{916,00} & \multirow{2}{*}{$-0,14$} & \multirow{2}{*}{0,89} \\
\hline
\end{tabular}

Tablo 4 incelendiğinde, cinsiyete göre yönetimin bakış açısı ve kurallar, GïÖ toplam puan ve İAN puanlarının arasında anlamlı bir farklılık yoktur $(p>0,05)$. Bununla birlikte, cinsiyete göre iş arkadaşları ve güvenlik eğilimleri puanları arasında anlamlı bir fark vardır $(p<0,05)$. Kadınların iş arkadaşları ve güvenlik eğilimleri puanı, erkeklerin puanından anlamlı olarak daha yüksektir.

Tablo 5. Medeni Duruma Göre Güvenlik İklimi ve İAN Puanlarının Mann-Whitney U Testi ile Karşılaştırılması

\begin{tabular}{|c|c|c|c|c|c|c|c|}
\hline Değişkenler & $\begin{array}{l}\text { Medeni } \\
\text { durum }\end{array}$ & $\mathrm{N}$ & SO & $\mathrm{ST}$ & $\mathrm{U}$ & $\mathrm{Z}$ & $\mathrm{p}$ \\
\hline \multirow{2}{*}{ Yönetimin Bakış Açısı ve Kurallar } & Evli & 68 & 66,69 & 4535,00 & \multirow{2}{*}{1823,00} & \multirow{2}{*}{$-0,89$} & \multirow{2}{*}{0,37} \\
\hline & Bekar & 59 & 60,90 & 3593,00 & & & \\
\hline \multirow{2}{*}{ İş Arkadaşları ve Güvenlik Eğilimleri } & Evli & 68 & 64,09 & 4358,00 & \multirow{2}{*}{2000,00} & \multirow{2}{*}{$-0,03$} & \multirow{2}{*}{0,98} \\
\hline & Bekar & 59 & 63,90 & 3770,00 & & & \\
\hline \multirow{2}{*}{ GïÖ toplam puan } & Evli & 68 & 66,17 & 4499,50 & \multirow{2}{*}{1858,50} & \multirow{2}{*}{$-0,72$} & \multirow{2}{*}{0,47} \\
\hline & Bekar & 59 & 61,50 & 3628,50 & & & \\
\hline \multirow{2}{*}{ İAN } & Evli & 68 & 60,46 & 4111,50 & \multirow{2}{*}{1765,50} & \multirow{2}{*}{$-1,17$} & \multirow{2}{*}{0,24} \\
\hline & Bekar & 59 & 68,08 & 4016,50 & & & \\
\hline
\end{tabular}

Tablo 5 incelendiğinde, medeni duruma göre yönetimin bakış açısı ve kurallar, iş arkadaşları ve güvenlik eğilimleri, GïÖ toplam puan ve İAN puanlarının anlamlı bir farklılık göstermemektedir ( $p>0,05)$. Bekar ve evli olan katılımcıların iş güvenliği algılarının ve İAN ‘nin benzer olduğu gözlenmiştir. 
Tablo 6. Çocuk Sahibi Olma Durumuna Göre Güvenlik İklimi ve İAN Puanlarının Mann-Whitney U Testi ile Karşılaştırılması

\begin{tabular}{|c|c|c|c|c|c|c|c|}
\hline Değişkenler & $\begin{array}{l}\text { Çocuğunuz } \\
\text { var mı? }\end{array}$ & $\mathrm{N}$ & $\mathrm{SO}$ & $\mathrm{ST}$ & $\mathrm{U}$ & $\mathrm{Z}$ & $\mathrm{p}$ \\
\hline \multirow{2}{*}{ Yönetimin Bakış Açısı ve Kurallar } & Evet & 59 & 63,27 & 3733,00 & \multirow{2}{*}{1963,00} & \multirow{2}{*}{$-0,21$} & \multirow{2}{*}{0,83} \\
\hline & Hayır & 68 & 64,63 & 4395,00 & & & \\
\hline \multirow{2}{*}{ İş Arkadaşları ve Güvenlik Eğilimleri } & Evet & 59 & 62,72 & 3700,50 & \multirow{2}{*}{1930,50} & \multirow{2}{*}{$-0,38$} & \multirow{2}{*}{0,71} \\
\hline & Hayır & 68 & 65,11 & 4427,50 & & & \\
\hline \multirow{2}{*}{ GïÖ toplam puan } & Evet & 59 & 63,33 & 3736,50 & \multirow{2}{*}{1966,50} & \multirow{2}{*}{$-0,19$} & \multirow{2}{*}{0,85} \\
\hline & Hayır & 68 & 64,58 & 4391,50 & & & \\
\hline \multirow{2}{*}{ İAN } & Evet & 59 & 62,08 & 3662,50 & \multirow{2}{*}{1892,50} & \multirow{2}{*}{$-0,55$} & \multirow{2}{*}{0,58} \\
\hline & Hayır & 68 & 65,67 & 4465,50 & & & \\
\hline
\end{tabular}

Tablo 6 incelendiğinde, çocuk sahibi olma durumuna göre yönetimin bakış açısı ve kurallar, iş arkadaşları ve güvenlik eğilimleri, GIOO toplam puan ve İAN puanlarının anlamlı bir farklılık göstermediği anlaşılmaktadır (p>0,05). Çocuk sahibi olan ve olmayan katılımcıların iş güvenliği algılarının ve İAN' nin benzer olduğu gözlenmiştir.

Tablo 7. Yaşa Göre Güvenlik İklimi ve İAN Puanlarının Kruskal Wallis H Testi ile Karşılaştırılması

\begin{tabular}{llllll}
\hline Değişkenler & Yaş grubu & N & SO & H & P \\
\hline & $18-25$ & 17 & 51,12 & & \\
& $26-33$ & 31 & 55,81 & & \\
Yönetimin Bakış Açısı ve Kurallar & $34-41$ & 26 & 78,00 & 8,43 & 0,08 \\
& $42-49$ & 41 & 63,62 & & \\
& 50 ve üzeri & 12 & 74,38 & & \\
\hline & $18-25$ & 17 & 47,35 & & \\
& $26-33$ & 31 & 56,61 & & \multirow{2}{*}{0,08} \\
İş Arkadaşları ve Güvenlik Eğilimleri & $34-41$ & 26 & 73,06 & 8,25 & \\
& $42-49$ & 41 & 67,43 & & \\
& 50 ve üzeri & 12 & 75,33 & & \\
\hline \multirow{4}{*}{ GïÖ toplam puan } & $18-25$ & 17 & 50,29 & & \\
& $26-33$ & 31 & 54,79 & & \\
& $34-41$ & 26 & 76,83 & 8,68 & \\
& $42-49$ & 41 & 65,26 & & \\
\hline İAN & 50 ve üzeri & 12 & 75,13 & & \\
& $18-25$ & 17 & 73,53 & & \\
& $26-33$ & 31 & 67,32 & & \\
& $34-41$ & 26 & 56,73 & 4,03 & \\
& $42-49$ & 41 & 59,22 & & \\
\hline
\end{tabular}

Tablo 7 incelendiğinde, yaş gruplarına göre yönetimin bakış açısı ve kurallar, iş arkadaşları ve güvenlik eğilimleri, GIOO toplam puan ve İAN puanlarının anlamlı bir farklılık göstermediği anlaşılmaktadır ( $>00,05$ ). 18-25, 26-33, 34-41, 42-49, 50 ve üzeri yaş gruplarında bulunan katılımcıların iş güvenliği algılarının ve İAN' nin benzer olduğu gözlenmiştir. 
Tablo 8. Çalışma Türüne Göre Güvenlik İklimi ve İAN Puanlarının Mann-Whitney U Testi ile Karşılaştırılması

\begin{tabular}{|c|c|c|c|c|c|c|c|}
\hline Değişkenler & $\begin{array}{l}\text { Çalışma } \\
\text { türü }\end{array}$ & $\mathrm{N}$ & SO & ST & $\mathrm{U}$ & $\mathrm{z}$ & $\mathrm{p}$ \\
\hline \multirow{2}{*}{ Yönetimin Bakış Açısı ve Kurallar } & $\mathrm{AF}$ & 52 & 80,29 & 4175,00 & \multirow{2}{*}{1103,00} & \multirow{2}{*}{$-4,17$} & \multirow{2}{*}{0,00} \\
\hline & $\mathrm{TF}$ & 75 & 52,71 & 3953,00 & & & \\
\hline \multirow{2}{*}{ İş Arkadaşları ve Güvenlik Eğilimleri } & $\mathrm{AF}$ & 52 & 76,88 & 3998,00 & \multirow{2}{*}{1280,00} & \multirow{2}{*}{$-3,38$} & \multirow{2}{*}{0,00} \\
\hline & $\mathrm{TF}$ & 75 & 55,07 & 4130,00 & & & \\
\hline \multirow{2}{*}{ GîÖ toplam puan } & $\mathrm{AF}$ & 52 & 80,19 & 4170,00 & \multirow{2}{*}{1108,00} & \multirow{2}{*}{$-4,15$} & \multirow{2}{*}{0,00} \\
\hline & $\mathrm{TF}$ & 75 & 52,77 & 3958,00 & & & \\
\hline \multirow{2}{*}{ İAN } & $\mathrm{AF}$ & 52 & 55,40 & 2881,00 & \multirow{2}{*}{1503,00} & \multirow{2}{*}{$-2,21$} & \multirow{2}{*}{0,03} \\
\hline & $\mathrm{TF}$ & 75 & 69,96 & 5247,00 & & & \\
\hline
\end{tabular}

Tablo 8 incelendiğinde, çalışma türüne göre yönetimin bakış açısı ve kurallar, iş arkadaşları ve güvenlik eğilimleri, GİÖ toplam puan ve İAN puanlarının anlamlı bir farklılık gösterdiği anlaşılmaktadır $(\mathrm{p}<0,05)$. Ana firma çalışanı katılımcıların yönetimin bakış açısı ve kurallar, iş arkadaşları ve güvenlik eğilimleri, GİÖ toplam puanları, taşeron firma çalışanı katılımcıların puanlarından anlamlı olarak daha yüksektir. Taşeron firma çalışanı katılımcıların İAN puanı ise ana firma çalışanı katılımcıların puanından anlamlı olarak daha yüksektir.

Tablo 9. Net Maaşa Göre Güvenlik İklimi ve İAN Puanlarının Kruskal Wallis H Testi ile Karşılaştırılması

\begin{tabular}{|c|c|c|c|c|c|c|}
\hline Değişkenler & Net maaş & $\mathrm{N}$ & $\mathrm{SO}$ & $\mathrm{H}$ & $\mathrm{p}$ & Fark \\
\hline \multirow[t]{5}{*}{ Yönetimin Bakış Açısı ve Kurallar } & 3000 TL ve altı ${ }^{a}$ & 8 & 71,31 & 10,19 & 0,04 & $\mathrm{e}>\mathrm{b}$ \\
\hline & $3001-4000 \mathrm{TL}^{\mathrm{b}}$ & 34 & 47,62 & & & \\
\hline & $4001-5000 \mathrm{TL}^{\mathrm{c}}$ & 40 & 65,90 & & & \\
\hline & $5001-6000 \mathrm{TL}^{\mathrm{d}}$ & 21 & 73,17 & & & \\
\hline & 6001 TL ve üstü e & 24 & 73,58 & & & \\
\hline \multirow[t]{5}{*}{ İş Arkadaşları ve Güvenlik Eğilimleri } & 3000 TL ve altı a & 8 & 64,50 & 11,55 & 0,02 & $\mathrm{e}>\mathrm{b}$ \\
\hline & $3001-4000 \mathrm{TL}^{\mathrm{b}}$ & 34 & 47,72 & & & \\
\hline & $4001-5000 \mathrm{TL}^{\mathrm{c}}$ & 40 & 66,10 & & & \\
\hline & $5001-6000 \mathrm{TL}^{\mathrm{d}}$ & 21 & 69,90 & & & \\
\hline & 6001 TL ve üstü e & 24 & 78,23 & & & \\
\hline \multirow[t]{5}{*}{ GïÖ toplam puan } & 3000 TL ve altı ${ }^{a}$ & 8 & 70,00 & 11,91 & 0,02 & $\mathrm{e}>\mathrm{b}$ \\
\hline & $3001-4000 \mathrm{TL}^{\mathrm{b}}$ & 34 & 46,25 & & & \\
\hline & $4001-5000 \mathrm{TL}^{\mathrm{c}}$ & 40 & 66,45 & & & \\
\hline & $5001-6000 \mathrm{TL}^{\mathrm{d}}$ & 21 & 72,71 & & & \\
\hline & 6001 TL ve üstü e & 24 & 75,44 & & & \\
\hline \multirow[t]{5}{*}{ İAN } & 3000 TL ve alt ${ }^{a}$ & 8 & 91,44 & 14,58 & 0,01 & $a>e$ \\
\hline & $3001-4000$ TL b & 34 & 70,96 & & & $\mathrm{~b}>\mathrm{e}$ \\
\hline & $4001-5000 \mathrm{TL}^{\mathrm{c}}$ & 40 & 67,99 & & & \\
\hline & $5001-6000 \mathrm{TL}^{\mathrm{d}}$ & 21 & 58,74 & & & \\
\hline & 6001 TL ve üstü e & 24 & 42,96 & & & \\
\hline
\end{tabular}

Tablo 9 incelendiğinde, net maaşa göre yönetimin bakış açısı ve kurallar, iş arkadaşları ve güvenlik eğilimleri, GİÖ toplam puan ve İAN puanlarının anlamlı bir farklılık gösterdiği anlaşılmaktadır $(p<0,05)$. 6001 TL ve üstü net maaşa sahip katılımcıların yönetimin bakış açısı ve kurallar, iş arkadaşları ve güvenlik eğilimleri, GïÖ toplam puanları, 3001-4000 TL net maaşa sahip katılımcıların puanlarından anlamlı olarak daha yüksektir. 3000 TL ve altı ve 3001-4000 TL net maaşa sahip katılımcıların İAN puanı ise 6001 TL ve üstü net maaşa sahip katılımcıların puanından anlamlı olarak daha yüksektir. 
Tablo 10. Eğitim Durumuna Göre Güvenlik İklimi ve İAN Puanlarının Kruskal Wallis H Testi ile Karşılaştırılması

\begin{tabular}{|c|c|c|c|c|c|c|}
\hline Değişkenler & Eğitim durumu & $\mathrm{N}$ & $\mathrm{SO}$ & $\mathrm{H}$ & $\mathrm{p}$ & Fark \\
\hline \multirow{5}{*}{ Yönetimin Bakış Açısı ve Kurallar } & İlkokul & 45 & 58,78 & \multirow{5}{*}{8,23} & \multirow{5}{*}{0,08} & \multirow{5}{*}{-} \\
\hline & Ortaokul & 32 & 54,86 & & & \\
\hline & Lise & 16 & 67,44 & & & \\
\hline & Ön lisans & 9 & 72,33 & & & \\
\hline & Lisans & 25 & 79,90 & & & \\
\hline \multirow{5}{*}{ İş Arkadaşları ve Güvenlik Eğilimleri } & İlkokul a & 45 & 59,70 & \multirow{5}{*}{15,72} & \multirow{5}{*}{0,00} & \multirow{5}{*}{$\begin{array}{l}e>a, \\
e>b,\end{array}$} \\
\hline & Ortaokul b & 32 & 50,30 & & & \\
\hline & Lise $^{c}$ & 16 & 65,19 & & & \\
\hline & Ön lisans ${ }^{d}$ & 9 & 68,61 & & & \\
\hline & Lisans e & 25 & 86,86 & & & \\
\hline \multirow{5}{*}{ GïÖ toplam puan } & İlkokul a & 45 & 58,84 & \multirow{5}{*}{11,28} & \multirow{5}{*}{0,02} & \multirow{5}{*}{$\begin{array}{l}e>a, \\
e>b,\end{array}$} \\
\hline & Ortaokul b & 32 & 52,48 & & & \\
\hline & Lise $^{c}$ & 16 & 67,41 & & & \\
\hline & Ön lisans d & 9 & 72,28 & & & \\
\hline & Lisans e & 25 & 82,86 & & & \\
\hline \multirow{5}{*}{ İAN } & İlkokul & 45 & 67,22 & \multirow{5}{*}{3,44} & \multirow{5}{*}{0,49} & \multirow{5}{*}{-} \\
\hline & Ortaokul & 32 & 65,72 & & & \\
\hline & Lise & 16 & 69,50 & & & \\
\hline & Ön lisans & 9 & 65,11 & & & \\
\hline & Lisans & 25 & 52,08 & & & \\
\hline
\end{tabular}

Tablo 10 incelendiğinde, eğitim durumuna göre yönetimin bakış açısı ve kurallar ve İAN puanlarının anlamlı bir farklılık göstermediği anlaşılmaktadır $(\mathrm{p}>0,05)$. Bununla birlikte, eğitim durumuna göre iş arkadaşları ve güvenlik eğilimleri ve GïÖ toplam puan puanları anlamlı bir farklılık göstermiştir $(p<0,05)$. Lisans mezunu katılımcıların iş arkadaşları ve güvenlik eğilimleri ve GïÖ toplam puanları, ilkokul ve ortaokul mezunu katılımcıların puanlarından anlamlı olarak daha yüksektir.

Tablo 11. Mesleki Tecrübeye Göre Güvenlik İklimi ve İAN Puanlarının Kruskal Wallis H Testi ile Karşılaştırılması

\begin{tabular}{|c|c|c|c|c|c|}
\hline Değişkenler & Mesleki tecrübe & $\mathrm{N}$ & $\mathrm{SO}$ & $\mathrm{H}$ & $p$ \\
\hline \multirow{3}{*}{ Yönetimin Bakış Açısı ve Kurallar } & 3 yıl ve daha az & 16 & 65,44 & \multirow{3}{*}{0,07} & \multirow{3}{*}{0,97} \\
\hline & $3-5$ yil & 24 & 62,44 & & \\
\hline & 5 yıl ve üzeri & 87 & 64,17 & & \\
\hline \multirow{3}{*}{ İş Arkadaşları ve Güvenlik Eğilimleri } & 3 yıl ve daha az & 16 & 58,28 & \multirow{3}{*}{0,62} & \multirow{3}{*}{0,73} \\
\hline & $3-5$ yil & 24 & 62,31 & & \\
\hline & 5 yıl ve üzeri & 87 & 65,52 & & \\
\hline \multirow{3}{*}{ GîO toplam puan } & 3 yıl ve daha az & 16 & 63,63 & \multirow{3}{*}{0,23} & \multirow{3}{*}{0,89} \\
\hline & 3-5 yil & 24 & 60,88 & & \\
\hline & 5 yıl ve üzeri & 87 & 64,93 & & \\
\hline \multirow{3}{*}{ İAN } & 3 yıl ve daha az & 16 & 64,06 & \multirow{3}{*}{0,04} & \multirow{3}{*}{0,98} \\
\hline & 3-5 y1l & 24 & 65,35 & & \\
\hline & 5 yil ve üzeri & 87 & 63,61 & & \\
\hline
\end{tabular}

Tablo 11 incelendiğinde, mesleki tecrübeye göre yönetimin bakış açısı ve kurallar, iş arkadaşları ve güvenlik eğilimleri, GiÖ toplam puan ve İAN puanlarının anlamlı bir farklılık göstermediği anlaşılmaktadır ( $>0,05)$. 3 yıl ve daha az, 3-5 yıl, 5 yıl ve üzeri mesleki tecrübeye sahip katılımcıların iş güvenliği algılarının ve İAN' nin benzer olduğu gözlenmiştir. 
Tablo 12. Mevcut Firmadaki Çalışma Süresine Göre Güvenlik İklimi ve İAN Puanlarının Kruskal Wallis H Testi ile Karşılaştırılması

\begin{tabular}{|c|c|c|c|c|c|}
\hline Değişkenler & Mevcut firmadaki çalışma süresi & $\mathrm{N}$ & $\mathrm{SO}$ & $\mathrm{H}$ & $\mathrm{p}$ \\
\hline \multirow{4}{*}{ Yönetimin Bakış Açısı ve Kurallar } & 1 yıldan az & 13 & 73,42 & \multirow{4}{*}{4,59} & \multirow{4}{*}{0,20} \\
\hline & $1-3$ yil & 25 & 61,80 & & \\
\hline & 3-5 yil & 22 & 76,09 & & \\
\hline & 5 y1l ve üzeri & 67 & 59,02 & & \\
\hline \multirow{4}{*}{ İş Arkadaşları ve Güvenlik Eğilimleri } & 1 yıldan az & 13 & 64,50 & \multirow{4}{*}{0,66} & \multirow{4}{*}{0,88} \\
\hline & $1-3$ yil & 25 & 63,80 & & \\
\hline & 3-5 y1l & 22 & 69,36 & & \\
\hline & 5 yıl ve üzeri & 67 & 62,22 & & \\
\hline \multirow{4}{*}{ GíÖ toplam puan } & 1 yıldan az & 13 & 71,81 & \multirow{4}{*}{3,06} & \multirow{4}{*}{0,38} \\
\hline & $1-3$ yil & 25 & 61,66 & & \\
\hline & 3-5 y1l & 22 & 73,91 & & \\
\hline & 5 y1l ve üzeri & 67 & 60,10 & & \\
\hline \multirow{4}{*}{ İAN } & 1 yıldan az & 13 & 76,12 & \multirow{4}{*}{2,63} & \multirow{4}{*}{0,45} \\
\hline & $1-3$ yil & 25 & 67,72 & & \\
\hline & $3-5$ y1l & 22 & 65,57 & & \\
\hline & 5 yil ve üzeri & 67 & 59,75 & & \\
\hline
\end{tabular}

Tablo 12 incelendiğinde, mevcut firmadaki çalışma süresine göre yönetimin bakış açısı ve kurallar, iş arkadaşları ve güvenlik eğilimleri, GïÖ toplam puan ve İAN puanlarının anlamlı bir farklılık göstermediği anlaşılmaktadır ( $p>0,05)$. Bulundukları firmada 1 yıldan az, 1-3 yıl, 3-5 yıl, 5 yıl ve üzeri süre ile çalışan katılımcıların iş güvenliği algılarının ve İAN'nin benzer olduğu gözlenmiştir.

Tablo 13. Mesleki Hayatta İş Kazası Geçirme Durumuna Göre Güvenlik İklimi ve İAN Puanlarının MannWhitney U Testi ile Karşılaştırılması

\begin{tabular}{|c|c|c|c|c|c|c|c|}
\hline Değişkenler & $\begin{array}{l}\text { Meslek hayatı iş } \\
\text { kazası geçirme } \\
\text { durumu }\end{array}$ & $\mathrm{N}$ & $\mathrm{SO}$ & ST & $\mathrm{U}$ & $\mathrm{z}$ & $\mathrm{p}$ \\
\hline \multirow{2}{*}{ Yönetimin Bakış Açısı ve Kurallar } & Evet & 24 & 93,00 & 2232,00 & \multirow{2}{*}{540,00} & \multirow{2}{*}{$-4,31$} & \multirow{2}{*}{0,00} \\
\hline & Hayır & 103 & 57,24 & 5896,00 & & & \\
\hline \multirow{2}{*}{ İş Arkadaşları ve Güvenlik Eğilimleri } & Evet & 24 & 87,81 & 2107,50 & \multirow{2}{*}{664,50} & \multirow{2}{*}{$-3,62$} & \multirow{2}{*}{0,00} \\
\hline & Hayır & 103 & 58,45 & 6020,50 & & & \\
\hline \multirow{2}{*}{ Gi̇Ö toplam puan } & Evet & 24 & 92,77 & 2226,50 & \multirow{2}{*}{545,50} & \multirow{2}{*}{$-4,27$} & \multirow{2}{*}{0,00} \\
\hline & Hayır & 103 & 57,30 & 5901,50 & & & \\
\hline \multirow{2}{*}{ İAN } & Evet & 24 & 55,90 & 1341,50 & \multirow{2}{*}{1041,50} & \multirow{2}{*}{$-1,21$} & \multirow{2}{*}{0,23} \\
\hline & Hayır & 103 & 65,89 & 6786,50 & & & \\
\hline
\end{tabular}

Tablo 13 incelendiğinde, iş kazası geçirme durumuna göre İAN puanlarının anlamlı bir farklılık göstermediği anlaşılmaktadır ( $p>0,05)$. Bununla birlikte, iş kazası geçirme durumuna göre yönetimin bakış açısı ve kurallar, iş arkadaşları ve güvenlik eğilimleri ve GïÖ toplam puan puanlarının anlamlı bir farklılık gösterdiği anlaşılmaktadır $(\mathrm{p}<0,05)$. Meslek hayatlarında iş kazası geçiren katılımcıların, iş kazası geçirme durumuna 
göre yönetimin bakış açısı ve kurallar, iş arkadaşları ve güvenlik eğilimleri ve GïÖ toplam puanları, iş kazası geçirmeyen katılımcıların puanlarından anlamlı olarak daha yüksektir.

Tablo 14. Mevcut Firmada İş Kazası Geçirme Durumuna Göre Güvenlik İklimi ve İAN Puanlarının MannWhitney U Testi ile Karşılaştırılması

\begin{tabular}{|c|c|c|c|c|c|c|c|}
\hline Değişkenler & $\begin{array}{l}\text { Firmada iş kazası } \\
\text { geçirme durumu }\end{array}$ & $\mathrm{N}$ & $\mathrm{SO}$ & ST & $\mathrm{U}$ & $\mathrm{z}$ & $\mathrm{p}$ \\
\hline \multirow{2}{*}{ Yönetimin Bakış Açısı ve Kurallar } & Evet & 48 & 71,32 & 3423,50 & \multirow{2}{*}{1544,50} & \multirow{2}{*}{$-1,76$} & \multirow{2}{*}{0,08} \\
\hline & Hayır & 79 & 59,55 & 4704,50 & & & \\
\hline \multirow{2}{*}{ İş Arkadaşları ve Güvenlik Eğilimleri } & Evet & 48 & 72,89 & 3498,50 & \multirow{2}{*}{1469,50} & \multirow{2}{*}{$-2,18$} & \multirow{2}{*}{0,03} \\
\hline & Hayır & 79 & 58,60 & 4629,50 & & & \\
\hline \multirow{2}{*}{ GïÖ toplam puan } & Evet & 48 & 72,26 & 3468,50 & \multirow{2}{*}{1499,50} & \multirow{2}{*}{$-1,98$} & \multirow{2}{*}{0,05} \\
\hline & Hayır & 79 & 58,98 & 4659,50 & & & \\
\hline \multirow{2}{*}{ İAN } & Evet & 48 & 54,92 & 2636,00 & \multirow{2}{*}{1460,00} & \multirow{2}{*}{$-2,18$} & \multirow{2}{*}{0,03} \\
\hline & Hayır & 79 & 69,52 & 5492,00 & & & \\
\hline
\end{tabular}

Tablo 14 incelendiğinde, çalışılan firmada iş kazası geçirme durumuna göre yönetimin bakış açısı ve kurallar ve GiÖÖ toplam puanlarının anlamlı bir farklılık göstermediği anlaşılmaktadır ( $p \geq 0,05)$. Bununla birlikte, çalışılan firmada iş kazası geçirme durumuna göre, iş arkadaşları ve güvenlik eğilimleri ve İAN puan puanlarının anlamlı bir farklılık gösterdiği anlaşılmaktadır $(p<0,05)$. Çalıştıkları firmada iş kazası geçiren katılımcıların iş arkadaşları ve güvenlik eğilimleri puanları, iş kazası geçirmeyen katılımcıların ise İAN puanları daha yüksek bulunmuştur.

Tablo 15. Güvenlik İklimi ve İAN Puanları Arasındaki İlişkilere Ait Spearman Korelasyon Katsayıları

\begin{tabular}{|c|c|c|c|c|c|}
\hline & Değişkenler & 1. & 2. & 3. & 4. \\
\hline 1. & Yönetimin bakış açısı ve kurallar & 1,000 & & & \\
\hline 2. & İş arkadaşları ve güvenlik eğilimleri & $0,775^{* *}$ & 1,000 & & \\
\hline 3. & GíÖ toplam puan & $0,978^{* *}$ & $0,884^{* *}$ & 1,000 & \\
\hline 4. & İAN & $-0,016$ & 0,022 & $-0,001$ & 1,000 \\
\hline
\end{tabular}

${ }^{* *} \mathrm{p}<0,01 ;{ }^{*} \mathrm{p}<0,05 ; \mathrm{N}=127$

Tablo 15 incelendiğinde, İAN puanları ile yönetimin bakış açısı ve kurallar ( $\mathrm{r}=-0,016$; $\mathrm{p}>0,05)$, iş arkadaşları ve güvenlik eğilimleri $(r=0,022 ; p>0,05)$ ve GïÖ toplam $(r=-0,001 ; p>0,05)$ puanları arasında istatistiksel olarak anlamlı olmayan ilişkilerin bulunduğu anlaşılmaktadır. Katılımcıların güvenlik iklimi algıları ile İAN arasında anlamlı bir ilişki bulunmamaktadır.

\section{SONUÇ ve TARTIŞMA}

Güvenlik iklimi algısı ve işten ayrılma niyeti arasındaki ilişkinin belirlenmesi için tasarlanmış olan bu çalışma Bilecik hızlı tren çalışanlarına uygulanmıştır. Verileri analiz etmek için toplam anket sayısı 127'dir. Yapılan istatistiki analizler sonucunda hızlı tren çalışanlarının iş güvenliği iklimi algıları ile işten ayrılma niyeti arasında anlamlı bir ilişki bulunmamaktadır. İş güvenliği iklimi algıları yüksek düzeyde iken, işten ayrılma niyeti orta düzeyde bulunmuştur. Şantiye ortamı ağır durumlarla sonuçlanabilecek iş kazalarına neden olduğu ve çok tehlikeli sınıfta bulunduğundan, özellikle 2012 yılında 6331 sayılı İs Sağlığı ve Güvenliği Kanunu'nun yürürlüğe girmesiyle beraber iş sağlığı ve güvenliği konusunun her geçen gün daha fazla önemsendiği çalışma alanlarıdır. Bu durum çalışanların sahadaki iş güvenliğine yönelik algı düzeylerinin bir göstergesi olan güvenlik iklimi ölçeği ortalama puanlarının yüksek çıkmasının bir nedeni olarak gösterilebilir.

Ayrıca sosyo-demografik değişkenlerle güvelik iklimi algısı ve işten ayrılma niyeti arasında istatistiki yönden bir farklılık olup olmadığı araştııılmış, cinsiyet değişkenine göre kadınların güvenlik iklimi ölçeğinin bir alt boyutu olan iş arkadaşları ve güvenlik eğilimleri puanı, erkeklerin puanından anlamlı olarak daha yüksek 
çıkmıştır. Katılımcıların gerek çalışma hayatı, gerekse şuan ki projede sahip oldukları mesleki tecrübeleriyle güvenlik iklimi ve işten ayrılma niyeti arasında anlamlı bir fark bulunmamaktadır. Çalışanların çalışma türüne göre ise, ana firma çalışanı katılımcıların yönetimin bakış açısı ve kurallar, iş arkadaşları ve güvenlik eğilimleri, güvenlik iklimi toplam puanları, taşeron firma çalışanı katılımcıların puanlarından anlamlı olarak daha yüksektir. Taşeron firma çalışanı katılımcıların işten ayrılma niyeti puanı ise ana firma çalışanı katılımcıların puanından anlamlı olarak daha yüksek çıkmıştır. Düşük örgütsel bağlılık çalışanların işten ayrılmalarına yol açarak (Tanveer, 2013), örgütsel sadakat, örgüt çalışanlarından uzun vadeli bağlılık alındığında sağlanır (Yang, 2012) düşüncesine uyum sağlayan bulgular elde edilmiştir. Çünkü taşeron firmaya bağlı çalışanların ana firmada çalışanlar kadar iş güvencesinin olmadığı bilinmektedir. 6001 TL ve üstü net maaşa sahip katılımcıların güvenlik iklimi algı düzeylerinin diğer katılımcılara göre, 3000 TL ve altı ile 30014000 TL net maaşa sahip katılımcıların İAN puanı ise 6001 TL ve üstü net maaşa sahip katılımcıların puanından anlamlı olarak daha yüksek bulunarak William'ın (2008) çalışmasıyla da desteklenmiştir.

Lisans mezunu katılımcların güvenlik iklimi algı puanlarının, ilkokul ve ortaokul mezunlarına göre daha yüksek olduğu hesaplanmıştır. İş kazası geçirme durumuna göre ise, iş kazası geçiren katılımcıların iş kazası geçirmeyen katılımcılara göre toplam güvenlik iklimi ve alt boyutlarının puanları anlamlı olarak daha yüksek çıkmıştır.

Çalışma ortamında çalışanların kendilerini güvende hissetmeleri önemli bir durumdur. Bu durumun olumsuz şartları kişilerde motivasyon eksikliği, iş stresi, performans düşüklüğü, tükenmişlik gibi olumsuzluklara neden olabileceği gibi, kişileri işlerinden memnuniyetsiz bir duyguya götürebilir. Bundan dolayı işten ayrılma niyetine girebilirler. Huang vd.'nin (2016) 6207 kamyon şoförü üzerinde yaptıkları çalışmada güvenlik iklimi ve işten ayrılma arasında negatif yönlü bir ilişki söz konusudur. Nixon'un (2015) sağlık sektöründe 326 hemşireye yaptığı anket sonuçlarına göre güvenlik iklimi ve işten ayrılmaya niyeti arasında bulunan negatif ilişki, Wang ve Chia-Dai (2015) tarafından Tayvan'da bulunan 268 televizyon muhabiri üzerinde yaptıkları araştırma ile desteklenmiştir.

İşten ayrılma konusunda yapılan çalışmalarda genellikle işten ayrılma niyetinin öncüllerinden bahsedilmektedir. Konu olan öncüller işle ilgili, işletmeyle ilgili, çalışanlarla ilgili ve dişsal faktörler olabilmektedir (Takase, 2010). Çalışmada, bu öncüllerden biri olduğu düşünülen iş güvenliği iklimi algısı ve işten ayrılma niyeti arasında anlamlı bir ilişki bulunmamış olsa da, farklı sektör ve çalışma alanlarında araştırılması faydalı olacaktır.

\section{KAYNAKÇA}

Abbasi, S. M., Hollman, K. W. ve Hayes, R. D. (2008). Bad bosses and how not to be one. Information Management Journal, 42, 52-56.

Bartlett, K. R. (1999). The relationship between training and organizational commitment in the health care field. Doctoral Dissertation. Illinois: The University of Illinois GSSS

Blau, G. ve Boal, K. (1989). Using job involvement and organizational commitment interactively to predict turnover. Journal of Management, 15(1), 115-127.

Büyüköztürk, Ş., Çakmak, E. K., Akgün, Ö. E., Karadeniz, Ş. ve Demirel, F. (2017). Bilimsel araştırma yöntemleri. Pegem Akademi.

Byrom, N. ve Corbridge, J. (1997). A tool to assess aspects of an organisations health \& safety climate. Proceedings of International Conference on Safety Culture in the Energy Industries, University of Aberdeen (1997, 22-24 Sept.

Chang, C.P. ve Chang, W.C. (2008) “Internal Marketing Practices and Employees' Turnover Intentions in Tourism and Leisure Hotels" The Journal of Human Resource and Adult Learning, 4(2):161-172

Cho, S., Johanson, M. M. ve Guchait, P. (2009). Employees Intent to Leave: A Comparison of Determinants of Intent to Leave versus Intent to stay., 28(3),374-381.

Choudhry, R. M., Fang, D. ve Mohamed, S. (2007). Developing a Model of Construction Safety Culture. Journal of Management in Engineering, Vol. 23(4), Page 207-212. 
Clarke, S. (2006). The relationship between safety climate and safety performance: A meta-analytic review. Journal of Occupational Health Psychology, 11, 315-327. doi: 10.1037/1076-8998.11.4.315

Cooper, M.D. (2000). Towards a Model of Safety Culture. Safety Science, 32 (6) (2000), pp. 111-136

Cox, S. J. ve Cheyne, A. J. T. (2000). Assessing safety culture in offshore environments. Safety Science, 34, 111129. http://dx.doi.org/10.1016/S0925-7535(00)00009-6

Cox, S. J. ve Flin, R. (1998). Safety culture: philosophers stone or man of straw. Work \& Stress, 12 (1998), pp. 189201

Deliorman, R.B., Boz, İ.T., Yiğit, İ. Ve Yıldız, S.. (2009). “Tükenmişliği Ölçmede Alternatif bir Araç: Kopenhag Tükenmişlik Envanterinin Marmara Üniversitesi Akademik Personeli Üzerine Uyarlanması", İstanbul Üniversitesi Yönetim Dergisi, Yı1:20, Say1:63,77 98.

Fallon, M. ve Rutherford, D. (2010). Hotel Management and Operations. New Jersey: John Wiley \& Sons Inc.

Flin, R. (1998). Safety condition monitoring: Lessons from “Man-made disasters". Journal of Contingencies and Crisis Management, 6, 88-92. doi: 10.1111/1468-5973.00076

Guldenmund, F. (2000). The nature of safety culture: a review of theory and research. Safety Science, 34 (2000), pp. $215-25$

Gürbüz, S. ve Şahin, F. (2016). Sosyal Bilimlerde Araştırma Yöntemleri(3. Baskı).Seçkin Yayıncılık, Ankara

Güzel, C. (2019). The mediating effect of organizational commitment and job satisfaction in the relationship between workplace incivility and turnover intention. Master Tezi. Ankara: Ortadoğu Teknik Üniversitesi.

Health and Safety Executive, (2005). A review of safety culture and safety climate literature for the development of the safety culture inspection toolkit, https://www.hse.gov.uk/research/rrpdf/rr367.pdf

(Erişim tarihi: 13.09.2021).

Hofmann, D. A., ve Stetzer, A. (1996). A cross-level investigation of factors influencing unsafe behaviors and injuries. Personnel Psychology, 49, 307-339. doi: 10.1111/j.1744-6570.1996.tb01802.x

Huang, Y. H., Lee, J., McFadden, A. C., Murphy, L. A. ve Zohar, D. (2016). Beyond safety outcomes: an investigation of the impact of safety climate on job satisfaction, employee engagement and turnover using social exchange theory as the theoretical framework. Applied Ergonomics, 55(July), 248-257.

Jafarova, F. (2018). X-Y kuşağı çalışanlarının iş tatmini, örgütsel bağlllık ve işten ayrılma niyetinin karşılaştırılması: Beyaz yakalı çalışanlar üzerine bir uygulama. Yüksek Lisans Tezi. İstanbul: İstanbul Aydın Üniversitesi SBE.

Karasar, N. (2014). Bilimsel araştırma yöntemi. (26.baskı). Ankara Nobel Yayınevi.

Kaur, B., Mohşndru. Ve Pankaj, (2013). Atecedents of Turnover Intentions: A Literature Review. Global Journal of Management and Business Studies 3(10):1219-1230

Neal, A., Griffin, M.A. ve Hart P. M. (2000). The impact of organizational climate on safety climate and individual behavior. Safety Science, 34 (2000), pp. 99-109,

Nixon, A. E., Lanz, J. J., Manapragada, A., Bruk-Lee, V., Schantz, A. ve Rodriguez, J. F. (2015). Nurse safety: How is safety climate related to affect and attitude?. Work \& Stress, 29(4), 401-419.

Rusbult, C. E., Farrell, D., Rogers G. ve Mainous III, A. G. (1988). Impact of exchange variables on exit, voice, loyalty, and neglect: An integrative model of responses to declining job satisfaction. Academy of Management Journal, 31(3), 599-627.

Takase, M. (2010) A Concept Analysis of Turnover Intention: Implications for Nursing Management. Collegian, 17, 3-12. https://doi.org/10.1016/j.colegn.2009.05.001.

Telli, E., Ünsar, A. ve Oğuzhan, A . (2012). Liderlik Davranış Tarzlarının Çalışanların Örgütsel Tükenmişlik Ve İşten Ayrılma Eğilimleri Üzerine Etkisi: Konuyla İlgili Bir Uygulama . Ejovoc (Electronic Journal of 
Z. F. Olcay 13/3 (2021) 2902-2915

Vocational Colleges) , 2 (2) , 135-150 . Retrieved from https://dergipark.org.tr/tr/pub/ejovoc/issue/5393/73150

Tett, R. P. ve Meyer, J.P., (1993). Job satisfaction, Organizational Commitment, Turnover Intention and Turnover: Path Analyses Based on Meta- Analytic Findings. Personnel Psychology, 46(2), 259-293.

Türen, U., Gökmen, Y., Tokmak, Ġ. ve Bekmezci, M. (2014). Güvenlik iklimi ölçeği"enin geçerlilik ve güvenilirlik çalışması, Süleyman Demirel Üniversitesi İktisadi ve İdari Bilimler Fakültesi Dergisi, 19(4), 171 190.

Wang, C. ve Chia-Dai Yen. (2015). Leadership and turnover intentions of Taiwan TV reporters : the moderating role of safety climate. Asian Journal of Communication. 25(3), 255-270.

Weisberg, J. (1994), Measuring workers burnout and intention to leave, International Journal of Manpower, Vol.15,No1, 4-14.

Zohar, D. (1980). Safety climate in industrial organizations: Theoretical and applied implications. Journal of Applied Psychology, 65(1), 96-102. https://doi.org/10.1037/0021-9010.65.1.96 